\title{
Generating Sustainable Value from Open Data in a Sharing Society
}

\author{
Thorhildur Jetzek $^{1}$, Michel Avital $^{2}$, and Niels Bjørn-Andersen ${ }^{3}$ \\ ${ }^{1}$ Copenhagen Business School \\ tj.itmacbs.dk \\ ${ }^{2}$ Copenhagen Business School \\ michel@avital.net \\ ${ }^{3}$ Copenhagen Business School \\ nba.itmecbs.dk
}

\begin{abstract}
Our societies are in the midst of a paradigm shift that transforms hierarchal markets into an open and networked economy based on digital technology and information. In that context, open data is widely presumed to have a positive effect on social, environmental and economic value; however the evidence to that effect has remained scarce. Subsequently, we address the question how the use of open data can stimulate the generation of sustainable value. We argue that open data sharing and reuse can empower new ways of generating value in the sharing society. Moreover, we propose a model that describes how different mechanisms that take part within an open system generate sustainable value. These mechanisms are enabled by a number of contextual factors that provide individuals with the motivation, opportunity and ability to generate sustainable value.
\end{abstract}

Keywords: Sharing society, Sustainable value, Value generating mechanisms, Open data.

\section{$1 \quad$ Introduction}

The impact of the digital revolution on our societies can be compared to the ripples caused by a stone thrown in water: spreading outwards and affecting a larger and larger part of our lives with every year that passes. One of the many effects is the emergence of an already unprecedented amount of digital data that is accumulating exponentially. Moreover, a central affordance of digitization is the ability to distribute, share and collaborate, and we have thus seen an "open theme" gaining currency in recent years [18]. These trends are reflected in the explosion of Open Government Data (OGD) initiatives around the world: governments striving to open access to various data-sources and making them available for use and re-use for commercial or other purposes. However, while hundreds of national and local governments have established OGD portals and are being followed by similar initiatives by international institutions, civil society organizations and even businesses, there is a general feeling that the open data initiatives have not yet lived up to their true potential. This feeling 
is not without good reason; the recent Open Data Barometer report highlights that strong evidence on the impacts of OGD is almost universally lacking [11].

This lack of evidence might, however, not be as surprising when we consider the complexity of the task at hand. How do we measure and evaluate something as complicated as the value of open data? And if we cannot show that value is generated how can these initiatives be sustained? Our take on this dilemma is that before we even start trying to evaluate, we need to develop a deeper understanding of to what ends (what it is we want to accomplish with open data) and by what means (how this can possibly happen). And due to the embryonic nature of the open data phenomenon, research on open data impacts and affordances is still lacking (see, for instance, [59]).

Our goal with this paper is to contribute to this gap in knowledge by developing a theory on how open data can generate sustainable value. We build on the notion that the world is at an inflection point, where technological advances and boundarycrossing social challenges have come together to create a paradigm shift. This notion was very evident at the 2014 Annual Meeting of the World Economic Forum in Davos, where the shift towards the sharing economy and the current social challenges faced by our societies were repeatedly mentioned. These social challenges are numerous and urgent, and both social, environmental and economic in nature. They range from economic inequality, unemployment and poor social conditions to chronic diseases and climate change.

Given the complexity and cross-boundary nature of these challenges, a new approach is necessary. In particular, we need an approach where social and technological progress co-evolves in order to generate value [37]. We would like to contribute towards such an approach through addressing the following research question: "How can use of open data stimulate the generation of sustainable value?" The definition of sustainable value represents a move away from the previously dominant economic value focus and moving towards a focus on proactive, concerted efforts of businesses, government institutions and the overall community in addressing social challenges in innovative and holistic ways that generate social, environmental and economic value for all stakeholders and future generations [50].

This theory development paper is structured as follows: We first elaborate on the recent trends discussed earlier based on a review of the literature, after which we build theoretical foundations. We propose that we are experiencing a paradigm shift in how people make decisions in their quest for creating and appropriating value enabled by the transformative power of information technology. These recent technical and social developments call for a re-interpretation of the behavioral assumptions used in some of our most prominent value theories. We proceed to discuss four value generating mechanisms that describe different paths through which the use of data can be transformed to value. Our contribution here is a framework that adds a new network-based dimension to the well-established market-based mechanisms of efficiency and innovation (exploitation and exploration). We propose that all four mechanisms interact within an ecosystem we call the sharing society, and that the interaction between the private and the public sectors via the different mechanisms can generate the synergies that are necessary to tackle the highly complicated social challenges we face. Finally, we visualize our theory with a nomological network that shows the 
relationship between the main antecedents that can enable and stimulate value generation from data, the value generating mechanisms and the resulting, sustainable value.

\section{Open Data Empowers the Sharing Society}

The industrial economy was primarily based on production, where Gross Domestic Product (GDP) was the key measure of economic activity, and buying and selling goods and services on the market became the basic foundation for the value generating mechanisms. A dichotomy of the state and the market was one feature of the industrial economy [38]. The state's responsibility was to create a structure around the goods that did not fit the market mechanisms, so-called market failures. However, continuing advances in digital technologies have started to disrupt the status quo by altering the way people think, live and work, and by rearranging value pools [30]. This development has led to entirely new forms of products and services that, in many cases, are based on data collection, data re-use and data sharing. The digital revolution, including the digitization of nearly all media, the ubiquity of Internet access, the proliferation of mobile phones and the growth of the Internet of Things, has created multiple affordances which subsequently require a change in the basic assumptions that are used when discussing value maximizing behavior.

First, the digital revolution has led to an explosion in the generation and availability of data. Digitization has affected two important features of data: 1) when data become easily accessible to more than one person at a time, they acquire the feature of non-rivalry and; 2) when marginal costs incurred by re-production and distribution are drastically reduced, re-use of data becomes economically feasible [35], [44]. Second, following the advent of the "open theme", data that have traditionally been locked up in closed repositories are now increasingly becoming open and available for use and re-use [18]. Openness has changed one important feature of digital data, namely, making them non-excludable. Accordingly, when opened up, digital data become a shared resource - a public good or what has been termed 'digital commons' [19]. Open data, particularly government data, have generated a great deal of excitement around the world for its potential to empower citizens, change how government works and improve the delivery of public services. The economic value potential from open data has also been celebrated, and recently estimated as the equivalent of 3 trillion USD per annum globally [29]. In short, computing and networking capabilities combined with openness are expected to drive massive social, political and economic change [24].

Most of the open data initiatives today are driven by governments around the world, the most important driver seemingly being their expectation that open data will stimulate the generation of considerable social, economic and environment value for their societies [22]; [58], [51]. These initiatives have either been fuelled by the political ideology of Open Government [25] or been focused on economic value generation, highlighting the potential of re-use of data for innovation and efficiency [21]. However, despite this interest, there is still not much evidence of value generation, probably as most of the open data initiatives are still in their infancy [11], [20], [59]. 
Thus far, most of the published material on value generation is based on predictions and hypotheses, and there is still considerable confusion regarding what needs to be done, who should do it and how (by what means), as well as why we are doing it and for whom (to what ends). For instance, the technological availability and accessibility of data need to be conceptually separated from the political openness required to drive transparency and accountability [57]. One is concerned with the usability of the resource; the other is a mechanism whereby data are being used for specific purposes.

Interestingly, in the 77 countries surveyed in the Open Data Barometer, less than one in 10 datasets (or 71 out of the 821 public datasets reviewed) were truly open, i.e., available online, in bulk, and under an explicit open license [11]. In most cases, datasets are provided in aggregate formats (often in XLS or CSV), or are not machine readable (PDF files). The Open Data Barometer report also points towards important issues of data quality and trustworthiness. Of the 113 datasets that were available in machine-readable and openly licensed form, researchers found 15 where the sustainability was questionable and 20 that were not up-to-date or published in a timely fashion [11]. Moreover, while recent developments with open data offer unprecedented access to large scale data sets on a huge variety of topics, successful use of such data requires a new set of technical skills and data literacy, that are currently in short supply. Finally, while technology enabled services are key to harnessing the value of data, they are often limited by problems with usability, searchability, language, sufficiency of technological infrastructure and availability of computers and Internet access for many segments of the general population [4]. We conclude that governments still have some way to go: from embracing the value potential of open data to actually implementing the required value generation enabling structures.

Our aim with this paper is to contribute to an improved conceptual clarity in this discussion by presenting an open system we call the sharing society. We define the sharing society as an open economic and social system in which information technology is leveraged to empower individuals, corporations, non-profits and governments with data that are shared, reused and transformed to sustainable value through different mechanisms.

Following [6], we assume that the goal of the social system is to maximize utility or what we have defined as sustainable value. We use Coleman's framework as a meta-theory to explain the micro to macro level relationship between use of open data and the generation of sustainable value. Coleman's framework underscores the mediating role of individuals in linking macro-level variables such as social structure and the behavior of the social system [31]. A theory which can generate macro-level empirical generalizations as specific propositions may be thought of as "a theory of individual action, together with a theory of how these actions combine, under specific rules, to produce systemic behavior" [6], p. 20. But how is the sharing society conceptually different from the industrial economy? In the following sections, we outline the basic assumptions for our theory on how open data can generate value in the sharing society. 


\section{Behavioral Assumptions for Value Generating Mechanisms}

Any theory comprises a set of assumptions from which empirical generalizations have been derived [32]. In the social sciences, a satisfactory explanation must ultimately be anchored in hypotheses or assumptions about individual behavior [12]. By making a set of explicit, behavioral assumptions, we can highlight that all macro-level, societal phenomena are inherently derived from human beliefs and actions, and that certain mechanisms mediate these actions between the initial conditions and the observed outcome. Since the core behavioral assumptions of a theory often form the foundation of its mechanistic explanations, it is crucial that these assumptions are explicitly defined and tested during the early stage of empirical research [49].

The classical economic model of strategic interaction assumes that people are (a) only concerned about bettering their own material situation, and (b) able to calculate the optimal strategy for doing so. However, new results from behavioral economics have cast doubt on these assumptions, as evidence shows that people are, in fact, concerned with unobservable payoffs such as reputation, fairness or the well-being of others [45]. Furthermore, people are also concerned with how actions taken today might affect their future well-being. Accordingly, we must consider the wider social impact as well as the sustainability of our current actions [9], [45], [47]. A number of dimensions that can make classical models of rationality somewhat more realistic, while sticking within the vein of fairly rigorous formalization are described in [46]. These include: (a) limiting the types of utility functions, (b) considering the possibility of people having a "multi-valued" utility function and (c) recognizing the costs of gathering and processing information.

The general willingness of people to generate sustainable value is not really contested, but measures have remained elusive, and hence the emphasis on material wealth in economic theory. However, while monetary based indicators offer a convenient way to measure and compare value, there is a cross-disciplinary consensus that we need a more inclusive measure of welfare or wellbeing [47]. In the field of economics, a number of initiatives propose a move beyond using Gross Domestic Product as a measure of a country's progress. Renewed attention has been given to the concept of public value in the e-government and public policy disciplines. The public value framework is based on the premise that public resources should be used to increase value, not only in an economic sense but also more broadly in terms of what is valued by citizens and communities [2], [33]. These trends have resulted in the development of new, broader measures, such as OECD's Better Life Index.

At the organizational level of analysis, the concept of shared value presents a similar ideology. The premise behind shared value is that by including the generation of social value in their strategies, private companies can improve their competitive advantage at the same time as they contribute to society [38].

While most of us would like to act for the good of society, we do not always have the means or the cognitive capability to do so. Most people have limited attention, suffer from status quo bias and choice overload, and are prone to procrastination [45]. Moreover, people typically do not apply sufficient cognitive effort to calculate an optimal strategy, resorting rather to heuristics which can be influenced by context [46]. 
Rationality of individuals is limited by the information they have, the cognitive limitations of their minds, and the finite amount of time they have to make a decision.

Bounded rationality is "behavior that is intendedly rational but only limitedly so" [46], p. xxiv. So construed, bounded rationality takes exception with the analytically convenient assumption of hyper-rationality but does not preclude a predominantly rational approach to the study of complex economic organization [56]. Given that people face a multi-dimensional value function with complex relationships between individual and social wellbeing and that we as individuals have limited cognitive ability to rationally choose between different options, we can conclude that collection and dissemination of different types of data and the conversion of these data to information and insight are a key resource.

As a foundation for our theory, we make two assumptions. The first is that individuals in general want to go beyond increasing their own material wealth in their value generation efforts. We assume that individuals will strive for sustainable value, including social, environmental and economic value, for all stakeholders and future generations [50]. Sustainable value generation can be the result of collaborative efforts or it can happen through traditional market exchange, but the context in which decisions are made must provide the motivation, opportunity and ability for sustainable value generation to happen.

The second assumption we make is based on the notion of bounded rationality. People will be able to make decisions closer to an "optimum" if provided with the right kind of information about the situation they face. Access to the right kind of information can therefore push the boundaries of our ability to choose rationally and contribute to the generation of sustainable value. This assumption goes across all the proposed value generating mechanisms, i.e., we assume that provided with new data and information, people will choose differently, and this will lead to a sustainable value generation that will happen via different but interlinked mechanisms.

\section{A framework of Four Value Generating Mechanisms}

In order to frame the different value generation strategies, we have formulated a taxonomy/framework consisting of four archetypical value generating mechanisms. The mechanisms are organized after two dimensions, as seen in Figure 1. The x-axis dimension categorizes value mechanisms on whether data are used predominantly to do things better (exploit current resources) or to do new things (explore new opportunities). The $y$-axis represents our contribution to this traditional classification. The market-based mechanisms are an offspring of the traditional monetary economy, but the "new" network-based mechanisms revolve around information sharing. Market based mechanisms have traditionally been focused on the generation of economic value, either through lower costs or increased profits and are based on classic economic theories of the likes of Williamson and Schumpeter [42], [55], [56]. However, all mechanisms in the sharing economy to some extent focus on generating sustainable value. All are important and all depend, to a certain degree, on collaboration of people, across the boundaries of organizations and sectors. 


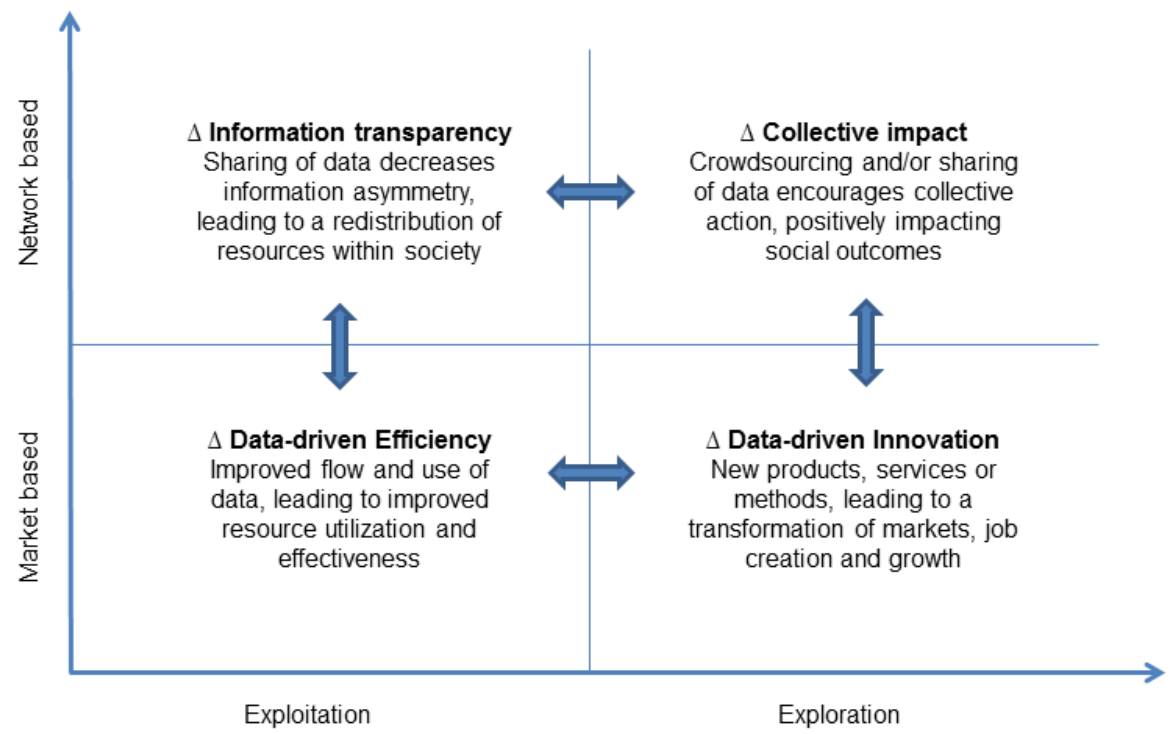

Fig. 1. A framework of four archetypical mechanisms that transform data to value

In the following list we summarize how these mechanisms work:

- Information transparency is gained if the data are available, accessible, accurate and trustworthy, and shine a light on a certain subject. The transparency mechanism generates value when individuals acquire new information that result in actions that further lead to a redistribution of resources.

- The collective impact mechanism generates value when a large group of individuals use data to collectively contribute to a common cause, positively impacting social outcomes.

- The data-driven efficiency mechanism generates value when stakeholders use data to improve productive efficiency and effectiveness, which can result in direct cost savings, saved time and effort, as well as improved quality of services.

- The data-driven innovation mechanism generates value when novel use of data leads to new innovative products, services or methods that transform markets and industries while generating jobs, profits and multiple other affordances, thus resulting in the generation of sustainable value.

\section{Generating Sustainable Value from Data in the Sharing Society}

Figure 1 shows the four archetypical mechanisms we propose that can transform data to value. We have, however, not explained how we can enable this value generation to happen, depending in all circumstances on the context in which the value generation happens. The model we present in Figure 2 is based on the macro-level model in [23], but it is extended to incorporate the findings from behavioral economics that 
explain the role and impact of individual behavior. A class of behavioral theories, based on the Motivation-Opportunity-Ability (MOA) framework, shows how motivation, opportunity and ability to perform certain tasks impact the behavior of individuals (see, for instance, [5] and Rheinolds et al., 2011). These models are commonly used in relation to social marketing and information processing [26], [40], public relations [15], knowledge sharing in workplaces [39], [43] and consumer behavior [60]. Broadly speaking, motivation can be defined as goal-directed arousal [26], [40]. In the context of this model, high motivation implies that individuals have the incentive to allocate resources to generate value from data; opportunity refers to the environmental or contextual factors that enable action; and ability represents the power or capacity to act [40].

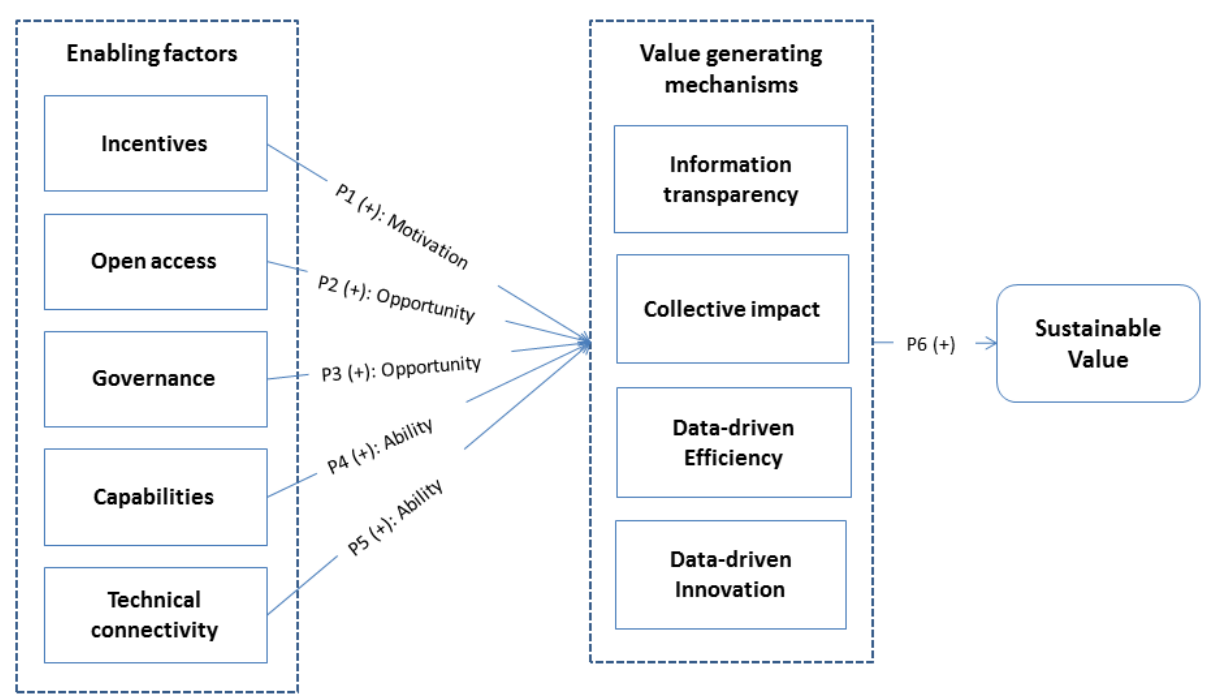

Fig. 2. A model of the sharing society - transforming data to value

We propose that policy makers can influence the motivation of users by offering incentives and the opportunity for value generation not only by supporting open access to data but also by providing risk-free and sustainable, high-quality data resources for internal and external users. Policy makers should also pay attention to the general ability of individuals to use these data by focusing on the availability of technical infrastructure as well as the general capabilities in society (although these two factors are, of course, also dependent on the provision of the market). We now briefly explain these enabling factors.

\subsection{Incentives}

The organizational leadership literature has shown that employees who are aware of the positive impact their behavior has on others are more motivated to make a pro-social 
difference, and that inspiration, a compelling vision and intellectual stimulation, likely enhances employees' motivation to actively engage in knowledge sharing [39]. Motivation can also influence companies to change institutions in order to support social practices, as can be seen in the many nonprofit organizations recently established by for-profit companies [53].

Following [53] and [45], we maintain that people not only chase visible carrots, but they also tend to consider the bigger societal-level impact of their actions, and are willing to participate in the "larger quest for the invisible gold at the end of the rainbow." We propose that by creating the right incentives, policy makers can motivate different stakeholders to use data to generate sustainable value. We have already seen a number of such efforts, most notably the relatively widespread Hackathons and Datapaloozas, which have been hosted by various municipal and state governments in order to encourage people from all sectors to consider the potential value of open data.

Proposition 1: Incentives positively influence the motivation of individuals to generate sustainable value from data in the sharing society, hence positively affecting each of the value generating mechanisms

\subsection{Open Access}

Providing open government data can be seen as a matter of availability, format, accessibility and license [10]. Opening access to data provides everyone in society with the opportunity to use these data to generate value. Openness is a key enabler for value generation from data, as it allows various users to re-use data for different purposes and therefore unlocks the intrinsic value that data hold [29].

The basic belief behind making the data available to external uses without restrictions is that the originator, owner or custodian of information or data may not be best placed to understand the potential future uses of the data they hold. Waste and the destruction of value could occur if government set rules of access to information which fails to recognize the requirements of unforeseen users and uses. In other words, too tight rules of engagement may unintentionally constrain the beneficial use by third parties or eventual end-users in the process of the diffusion of innovation. Moreover, openness should combine unrestricted availability of data with accessibility and technical interoperability [48]. Therefore, in addition to the general availability, an important dimension to open data is that there should be no legal or technical barriers to use and re-use. Use of open licenses and open data standards can facilitate the re-use of these data.

Proposition 2: Open access positively influences the opportunity for individuals to generate sustainable value from data in the sharing society, hence positively affecting each of the value generating mechanisms

\subsection{Governance}

When opened up, data become a common, shared resource, available for use within an open network of public and private stakeholders. However, this resource is still 
governed by the main collector or creator of the data. Therefore, we include governance as a construct that is intended to reflect the importance of data governance for the value that can be extracted from the resource. Based on [23], we conceptualize governance as a construct that describes the quality and sustainability of the data resource, where sustainability means that the common resource must meet the current needs of many individuals without compromising the ability of future generations to utilize the resource [19].

Data governance must consider data quality, data management, data policies, business process management and risk management. Data governance ensures that data can be trusted and that privacy is guarded. Making data accessible and ensuring it is fit for re-use are not insignificant challenges and such efforts raise a wide range of complex questions, including questions on how and when sharing is appropriate [18]. Without governance, the risks of using the data resource for mission critical purposes might become too high, and the data might not come at the right time or be in the right granularity to be of use for information purposes.

Proposition 3: Governance positively influences the opportunity of individuals to generate sustainable value from data in the sharing society, hence positively affecting each of the value generating mechanisms

\subsection{Capabilities}

As open government data are common, shared resources, the generative ability of the value generating mechanisms depends on certain capabilities in society. A capability can be defined as a measure of the ability of an entity to achieve an objective. In our case, it is the collective ability of individuals and organizations to use and re-use the data. Following [19], we emphasize the need for equitable use of the data resource. Citizen's access to the Internet and their ability to utilize the provided information are considered important for ensuring equitable dissemination [4], [16]. The digital divide can be broadly defined as the gap between those who have access to technologies and those who do not; however, there are, in fact, multiple divides that can exist, of which access to technology is but one. These issues include technology literacy as the ability to understand and use technology, as well as the ability of persons with disabilities to access the content through adaptive technologies [4]. Without the capabilities to access, use and make sense of data, the generative ability of the mechanisms becomes limited.

Proposition 4: Capabilities positively influence the ability of individuals to generate sustainable value from data, hence positively affecting each of the value generating mechanisms

\subsection{Technical Connectivity}

The current trend towards a massive increase in the generation of data, as well as wider access to different kinds of data, has important implications for both public and 
private organizations. This trend is supported by recent advances in technology: the technical ability to manage and openly disseminate big and small datasets; the ability to analyze, mash up and make sense of different types of data; and the networking capabilities to access and link data from various sources. Research suggests that the scale and scope of changes brought on by use of data are set to expand greatly as series of technology trends accelerate and converge. To capture value from data, public and private organizations will have to deploy technologies that can help individuals and organizations to integrate, analyze, visualize and consume the growing torrent of available data [28].

Technical connectivity is conceptualized as a construct that describes the availability of technologies that allow users to store, access, combine and analyze the data. The construct consists of three dimensions: 1) the infrastructure that facilitates data exchange between government agencies, private sector firms and the public, 2) dissemination of software, including data organization management software, as well as analytics and discovery software and 3) access via multiple platforms, such as mobile and web-based platforms.

Proposition 5: Technical connectivity positively influences the ability of individuals to generate sustainable value from data, hence positively affecting each of the value generating mechanisms

\subsection{The Generation of Sustainable Value}

Following is a short description of the main premises of our suggested model:

- Due to the complexity and cross-boundary nature of today's social challenges, societies need to support various different value generating mechanisms.

- These mechanisms account for the way in which sustainable value can be generated from the use of data. All of the mechanisms are dependent on some sort of collaborative efforts, but these can either be network based or market based.

- All of the mechanisms are dependent on the motivation, opportunity and ability of people to generate value from data.

- While the mechanisms function independently, they can and will interact within an ecosystem of mechanisms called the sharing society, and this interaction can generate valuable synergies.

- The sharing society is defined as an open economic and social system in which information technology is leveraged to empower individuals, corporations, nonprofits and government with data that are shared and reused and transformed to sustainable value through different mechanisms.

- The mechanisms contribute to the generation of sustainable value by creating different types of value: increase GDP through means such as corporate profits, job creation and tax payments; contribute to society by improving the general wellbeing of individuals through means such as better health, education, social inclusion or equality; or contribute to the livability of the environment through means such as reduced emissions, less traffic congestion or access to clean water. 
Proposition 6: Sustainable value is generated through a system of value generating mechanisms within the sharing society, both directly and through synergies between the mechanisms

\section{Discussion: The Transformative Power of Data}

We face many social challenges in this world. While none of the challenges has simple solutions, or can be solved by individual stakeholders or groups, there are ways to overcome many of these challenges - if we utilize the power of the sharing society. The market, by itself, oftentimes lacks the incentives and appropriate models to solve many of these issues, often called market failures. The payback in most market transactions is defined by an implicit or explicit contract, and its timing occurs closely behind, or simultaneous to, the initial contract. Within areas such as public health and social issues, the monetary payback, however, is often vague, uncertain and in the distant future [40].

Market failures are thus currently considered to be either the responsibility of the state or of civil society [38]. However, in many cases the silos of government departments are poorly suited to tackling complex problems that cut across sectors and nation states. Civil society might also lack the capital, skills and resources to take promising ideas to scale [34]. We thus propose that an informal collaboration between the public and private sectors, enabled by openly sharing and re-using data and information can positively influence the generation of sustainable value.

The model of the sharing society shows the potential progress from using data under different contexts, to the mechanisms that explain how the value generation happens, to the actual impact or output - the sustainable value that is generated. We wish to suggest a potential answer to the to what ends question, by highlighting the social challenges we are facing today and by showing how different governments and companies have together addressed some of these challenges by using open data. We also wish to delve deeper into the question of by what means by pointing out that use of data can generate value through different mechanisms (although these mechanisms interact and influence each other) and by highlighting the importance of the context in which value generation happens. Thus far, there has not been much scientific evidence to support the hypothesis of a link between opening access to government data and value generation. However, the relationship between use of data, the enabling factors, the different mechanisms, and value generation and appropriation can be illustrated with anecdotal evidence. This will be provided below, where we are suggesting possible value generation potentials to four of the largest societal challenges.

\subsection{Challenge Number 1: Economic Inequality}

One of the most acute social challenges we face today is the issue of economic inequality within or between nations. While economic inequality might primarily be seen as a violation of social justice, research shows that growing economic inequality since the mid-1970s has contributed to dysfunctional economies. It has even been 
linked to the recent economic crisis with devastating effects [14], [52]. Inequality is crystallized in a skewed allocation of resources, where the majority of society's resources belongs to certain groups enjoying more opportunities than do others.

To a certain degree, uneven distribution of resources is a part of the capitalistic society's market-based mechanisms. However, in some cases, resources are not allocated in a socially optimal way due to behavior such as opportunism and even corruption. Such outcomes are usually possible where there is an asymmetry of information between people, undermining accountability. Information asymmetry conceals skewed resource allocations which too often prioritize the interests of business, political and military elites over development priorities of the majority of the population.

\section{Transparency and Accountability to Combat Inequality}

Transparency refers to the absence of asymmetric information. Information transparency is a characteristic of governments, companies, organizations and individuals that are open to the clear disclosure of information, rules, plans, processes and actions. ${ }^{1}$ Information transparency can contribute to improved social outcomes by generating incentives and reducing uncertainty. Increased transparency in an organization's operation increases the outside stakeholders' capacity to hold the insiders accountable and provides stakeholders with information they can use in their own decision making. The transparency mechanism is essentially network based, as it depends on multiple instances of sharing and receiving of information between stakeholders. Eventually, increased transparency should facilitate equitable and effective allocation of resources across boundaries. In the context of accountability, transparency-enhancing mechanisms involving a multitude of stakeholders throughout society can be thought of as creating millions of "auditors" [3]. This "auditing" can mobilize resources from being used where they benefit few at the cost of many, to being used in a more socially responsible manner.

One such transparency agenda for tackling poverty in the global economy was presented by the British Prime Minister, David Cameron, in the G8 meeting at the World Economic Forum in Davos in January, 2013. The plan was to tackle illicit financial flows, the hidden company ownership that makes such flows possible, and land grabs in developing countries. The claim is that citizens in developing countries are regularly robbed of the benefits of their countries' mineral wealth through poorly negotiated or corrupt backroom deals. Collective global action is essential to improve the transparency of land transactions, thereby attracting more responsible investment that will contribute to sustainable economic growth and reduced poverty. ${ }^{2}$ In this case, open access to government data on company ownership, natural resources and taxes enables greater cross-border transparency. Interestingly, key datasets such as Land Registries and Company Registries are least likely of all the datasets reviewed in the Open Data Barometer to be available as open data, suggesting that OGD initiatives are not yet securing the release of politically important datasets that can be vital to

\footnotetext{
http://www.transparency-initiative.org/about/definitions

https: / / www.gov.uk/government/publications/uk-g8-presidencyreport -2013
} 
holding governments and companies accountable [11]. However, as a part of the G8 transparency agenda, the UK has committed to establishing a publicly accessible central registry of company beneficial ownership, and is undertaking a wider review of corporate transparency.

\subsection{Challenge Number 2: The Climate Challenge}

Climate change has emerged as one of the most important economic policy issues of the early 21 st century. The pollutants that contribute to global warming are commonly known as greenhouse gas emissions. Carbon dioxide $\left(\mathrm{CO}_{2}\right)$ is probably the best known greenhouse gas, representing $85 \%$ of all greenhouse gasses in the U.S. Electricity production is the largest single source of global warming pollution in the U.S., responsible for nearly $40 \%$ of greenhouse gas emissions ${ }^{3}$. A McKinsey report published in July 2009 estimated that there was a huge potential for energy-efficiency increases in the U.S., and that a $23 \%$ reduction in energy usage was possible by 2020 [27].

The study also highlighted a number of barriers to the realization of significant efficiency gains, including large initial outlays of capital required to improve infrastructure, the fragmentation of efficiency opportunities, societal apathy and simple lack of awareness. While the overall potential for energy-efficiency gains was vast, it was spread out across industrial, commercial and residential buildings, making widespread cooperation difficult. Additionally, the incentive and motivation of individuals and corporations to take responsibility for improvements by themselves were seen as being low [27].

\section{Provision of Information can Enable Collective Impact}

A green growth agenda requires policy makers to examine and influence behavior in a way that collectively impacts economic, social, and environmental outcomes on multiple scales [54]. Collective impact can be defined as the commitment of a group of actors from different sectors to a common agenda for solving a complex social problem [17]. As the prevailing characterization of human decision making in policy circles has until recently been a rational economic one, a wide range of factors that affect how people make decisions has been excluded from consideration and therefore needs to be considered in predictions of human reactions to environmental conditions or proposed policy initiatives [54].

Results from behavioral science have shown that providing high-energy consuming households with prescriptive normative information regarding the average home energy usage in their neighborhood constructively decreased energy consumption. For those that were doing better than the average, adding an injunctive component to the message (a smiley token) proved reconstructive by re-affirming their "good behavior" [36], [41]. The lesson is: People do not want to just save energy. They want to get information on how they are doing, and most importantly, to be acknowledged for their efforts.

3 http://www.epa.gov/ghgreporting/ghgdata/reported/index.html 
Opower is an energy tech company with a mission: to motivate everyone on earth to save energy. Opower was founded on a simple premise: to engage the millions of people who are in the dark about their energy use. To do so, they provide people with information on their own energy consumption as compared to other similar households, thereby putting every customer's energy use in personal perspective. Opower merges and analyzes utility and open government data to create individual customer profiles, and subsequently uses these profiles to generate personalized insights that are delivered through various channels. In February 2014, the Opower home energy reports helped people around the world to save over 3.7 terawatt hours of energy and more than $\$ 417$ million on their energy bills. We propose that policy makers, civil society and private companies can use different types of collaboration platforms to influence behavior. These platforms should provide people with relevant information as well as feedback mechanisms that enable them to respond to this information.

\subsection{Challenge Number 3: Efficient Use of Public Resources}

The importance of the efficient use of public resources for economic growth and stability, as well as for general well-being has been brought to the forefront by a number of developments over the past decades [1]. During the last 20 years, with the advent of the computer and the Internet as general technologies, a big portion of all processes in industrialized societies has become digitized. Research has shown that ICT has offered the capacity to reduce costs, increase the capability of machinery and increase flexibility in production planning and scheduling, thereby positively influencing productivity and efficiency.

During the initial stage of ICT adoption, many different systems were implemented, each with a specific purpose in mind, including payroll, human resources, production systems, resource planning, etc. This resulted in silos of disparate datasets in no way interconnected or integrated, causing various operational inefficiencies that included the same data being collected and hosted in different places, inability to automate processes across organizational boundaries and considerable overhead from trying to make sense of heterogeneous data sources. As an example, the costs incurred by recreating, verifying and transforming building information were estimated at $\$ 15.8$ billion in the U.S. capital facilities supply chain for 2002 alone [8].

\section{Efficient Use of Data Sets Resources Free}

Increasing cross-boundary interactions and higher levels of information exchange between citizens and government due to digitization have increased the total amount of government data collected and stored. These trends call for more efficient processing of data in order to provide the expected services while still keeping costs under control [7]. Efficiency of public sector organizations can be gained by cutting processing costs, making strategic connections between and among government agencies, and creating empowerment [13]. This allows for better utilization of valuable resources, either by directing them from non-value adding to value adding tasks, or by reducing use in order to increase sustainability. 
The Danish government has started an initiative where from 2012 to 2016 all basic government data will be improved in quality and context, and collection and dissemination of the data will be coordinated within the public sector. A national information infrastructure will be established for distribution of government data, with the aim of making the administration of the basic data registers easier and more efficient. Furthermore, as data will be freely available online, costs related to user support and billing are also expected to be reduced. The total yearly savings for the public sector are projected to be around $\$ 48$ million $^{4}$.

The focus of the Danish authorities is on collective savings. The business case calculated would not have been positive for individual institutions or agencies due to the large initial costs incurred by making these big changes to the data model, data quality and data distribution channels. By ensuring a positive internal business case for this initiative, the Danish authorities have increased the likelihood of the initiative being economically sustainable. Moreover, the positive external effect from this project is that integrated government data of better quality will also benefit private industries, such as real estate dealers, insurance companies, the financial sector and the telecom industry, which previously had to spend resources on creating usable information from heterogeneous data-sources. The cost-savings for the private industry are estimated to be around $\$ 90$ million per annum when the program is fully implemented.

\subsection{Challenge Number 4: Urban Planning}

Urbanization, the demographic transition from rural to urban, is associated with shifts from an agriculture-based economy to mass industry, technology and service. A hundred years ago, $20 \%$ of the global population lived in an urban area; by 1990, just under $40 \%$ of this population lived in cities; However, since 2010, for the first time ever, more than half of the world's population is living in urban areas. As this proportion continues to grow, by 2050, it is projected to have increased to seven out of 10 people. ${ }^{5}$ With urban congestion on the rise, city planners are looking for new ways to improve transportation. According to the Texas Transportation Institute, the cost of congestion in the U.S. in 2012 was more than $\$ 120$ billion, nearly $\$ 820$ for every commuter. ${ }^{6}$ Similar problems are endured by most of the world's bigger cities.

\section{Data-Driven Innovation to Ease Traffic Congestion}

Following Schumpeter, we assume that innovation can have economy-wide effects. Innovation brings about novel combinations of resources, and new production methods which, in turn, can lead to the transformation of markets and industries, thus increasing value [42]. The traditional definition of innovation builds on the underlying motive to generate economic value. Numerous studies have confirmed that

\footnotetext{
4 http://www.digst.dk/Servicemenu/English/Digitisation/ / media/Files/English/Grunddata_UK_web_05102012_Publication.pdf

5 http://www. who.int/gho/urban_health/situation_trends / urban_population_growth_text/en/

6 http://d2dt15nnlpfror.cloudfront.net/tti.tamu.edu/documents/ tti-umr.pdf
} 
innovative companies generate above-average returns and that innovative nations enjoy more economic growth.

Innovation, however, can also have clear social consequences. For instance, the computer has dramatically enhanced individual productivity, learning and creativity, and the World Wide Web has enabled the connectivity that has had disruptive effects on many societies, in some cases threatening dictatorship and corruption. In order to generate sustainable value, the innovation must at the very least not have negative social or environmental consequences, and optimally lead to the simultaneous generation of social, environmental and economic value. We use the term innovation to describe the mechanism that uses market forces to allocate resources in order to create a new method, product or service that generates sustainable value.

An increasing number of governments and cities in the world have started to publish open geospatial and traffic data. Many innovative solutions are currently being developed in addition to these data. One example is INRIX, a leading provider of traffic services with the goal of solving traffic worldwide. Their traffic intelligence platform analyzes data from public and private sources, including government road sensors, official accident and incident reports and data on real-time traffic speed, crowdsourced from a large community of local drivers. The company's analysis of crowdsourced data in combination with information from traditional sources provides drivers with insights that help them choose the best way to go, minimizing the amount of time spent.

As the app used to source traffic information from individuals is available for free, INRIX's main source of income is from car-producers, GPS providers and media companies. Moreover, they have recently started to provide data and tools to public information services. In particular, the crowd-sourced data allow much faster congestion analysis than was previously possible. ${ }^{7}$ This will allow public traffic engineers to measure and track congestion, thereby offering public decision makers better tools to analyze and manage transportation infrastructure for improved urban planning.

\section{Conclusions}

Our aim with this paper is to generate a theory that can explain the causal connections between use of open data and the consequent generation of sustainable value. We propose that the challenges faced by our societies urgently call for new forms of collective action between public and private stakeholders, and that we can move towards such collective action by actively sharing and re-using data across boundaries.

The first contribution of this paper is a new interpretation of the underlying behavioral assumptions. We propose that we are experiencing a paradigm shift in how people interact, enabled by the transformative power of information technology. This calls for a re-interpretation of some of the most prevalent behavioral assumptions underlying our current value theories. We propose that most people are driven not only by the wish to improve their own material situation, but also by the need for

\footnotetext{
7 http://tti.tamu.edu/2010/01/11/

texas-transportation-institute-teams-with-inrix/
} 
subjective well-being and the wish to be a contributing member of society. While opportunism and corruption are certainly relevant behaviors, they can be influenced by social norms. Acknowledging [46], [55], [56]; we further propose that bounded rationality is a reasonable approximation of how people behave but that the boundaries of rationality can be affected, for instance, by providing people with information.

The second contribution is a framework that adds a new dimension to the wellestablished market-based mechanisms of efficiency and innovation (exploitation and exploration), containing two network-based mechanisms that generate value through information transparency and collective impact. We propose that all four mechanisms interact within an ecosystem we call the sharing society, and that these interactions are capable of generating synergies in value creation. All the mechanisms are dependent on the private and public sector, together providing the motivation, opportunity and ability to generate value from data.

The third and final contribution is the nomological network, where we visualize our theory and show the main antecedents that enable data to be transformed to sustainable value via the sharing society system of mechanisms. These antecedents are supposed to reflect the context within which value generation happens, a context that can differ a great deal between countries and initiatives. We propose that the motivation, opportunity and ability of individuals to use data for value generation are influenced by: the incentives provided; the level of technical and legal openness of data; the maturity of resource (data) governance; the general data-related capabilities in society; and the technological maturity and prevalence. The motivation, opportunity and ability of individuals positively influence the different mechanisms that eventually explain how use of data is transformed to sustainable value.

This paper is limited initially moving only towards theory development; the next step is to use empirical data to test the relationships proposed here. As both open data and the sharing society are emerging phenomena, there is still not much theory to build upon; however, we are able to borrow from established value generation theories and current research on open data and behavioral economics. Future developments and continuing research will have to testify whether or not the proposed relationships hold or not.

\section{References}

1. Afonso, A., Schuknecht, L., Tanzi, V.: Public sector efficiency: Evidence for new EU member states and emerging markets. Applied Economics 42(17), 2147-2164 (2010)

2. Benington, J.: From Private Choice to Public Value? In: Benington, J., Moore, M. (eds.) Public Value: Theory and Practice, pp. 31-52. Palgrave MacMillan, Basingstoke (2011)

3. Bellver, A., Kaufmann, D.: Transparenting Transparency: Initial Empirics and Policy Applications. World Bank Policy Research Working Paper (2005),

http: / / tinyurl.com/k77rvlj

4. Bertot, J.C., Jaeger, P.T., Grimes, J.M.: Using ICTs to create a culture of transparency: Egovernment and social media as openness and anti-corruption tools for societies. Government Information Quarterly 27(2010), 264-271 (2010) 
5. Blumberg, M., Pringle, C.D.: The missing opportunity in organizational research: Some implications for a theory of work performance. Academy of Management Review 7(4), 560-569 (1982)

6. Coleman, J.C.: Foundations of Social Theory. Harvard University Press, Boston (1990)

7. Cordella, A.: E-government: towards the e-bureaucratic form? Journal of Information Technology 22(2007), 265-274 (2007)

8. Curry, E., O`Donnell, J., Corry, E., Hasan, S., Keane, M., O`Riain, S.: Linking building data in the cloud: Integrating cross-domain building data using linked data. Advanced Engineering Informatics 27(2013), 206-219 (2013)

9. Daly, H.E., Cobb, J.B.: For the Common Good: Redirecting The Economy toward Community, The Environment and A Sustainable Future, 2nd edn. Beacon Press, Boston (1994)

10. Davies, T.: Open data, democracy and public sector reform: A look at OGD use from data.gov.uk (2010), http: / / tinyurl.com/7joks 46

11. Davies, T.: Open Data Barometer: 2013 Global Report (2013), http: / /www. opendataresearch.org/dl /odb2013/Open-DataBarometer-2013-Global-Report.pdf

12. Elster, J.: Explaining Social Behavior. Cambridge University Press, Cambridge (2007)

13. European Commission: eGovernment Economics Project (eGEP), Measurement Framework Final. DG Information Society and Media, European Commission (2006)

14. Goldberg, G.S.: Economic inequality and economic crisis: a challenge for social workers. Social Work 57(3), 211-224 (2012)

15. Hallahan, K.: Enhancing Motivation, Ability, and Opportunity to Process Public Relations Messages. Public Relations Review 26(4), 463-480 (2000)

16. Halonen, A.: Being Open about Data (2012), http: / / inyurl . com/c8mz5vt

17. Hanleybrown, F., Kania, J., Kramer, M.: Channeling Change: Making Collective Impact Work. Stanford Social Innovation Review (2012)

18. Harrison, T.M., Pardo, T.A., Cook, M.: Creating Open Government Ecosystems: A Research and Development Agenda. The Future Internet 4(4), 900-928 (2012)

19. Hess, C., Ostrom, E.: Understanding Knowledge as a Commons - From Theory to Practice. MIT Press, Cambridge (2006)

20. Hujiboom, N., Van den Broek, T.: Open data: An international comparison of strategies. European Journal of e Practice $\mathrm{n}^{\circ} 12$ (2011)

21. Jansen, K.: The influence of the PSI directive on open government data: An overview of recent developments. Government Information Quarterly 28(4), 446-456 (2011)

22. Janssen, M., Charalabidis, Y., Zuiderwijk, A.: Benefits, Adoption Barriers and Myths of Open Data and Open Government. Information Systems Management 29(4), 258-268 (2012)

23. Jetzek, T., Avital, M., Bjørn-Andersen, N.: Generating Value from Open Government Data. In: Proceedings of the 34th International Conference on Information Systems, Milan, Italy (2013)

24. Kundra, V.: Digital Fuel of the 21st Century: Innovation through Open Data and the Network Effect. Joan Shorenstein Center on the Press, Politics and Public Policy, Harvard, Boston (January 2012)

25. Luna-Reyes, L.F., Bertot, J.C., Mellouli, S.: Open Government, Open Data and Digital Government. Government Information Quarterly 31(1), 4-5 (2013)

26. MacInnis, D.J., Moorman, C., Jaworski, B.J.: Enhancing Consumers' Motivation, Ability, and Opportunity to Process Brand Information from Ads: Conceptual Framework and Managerial Implications. Journal of Marketing 55(1991), 32-53 (1991) 
27. McKinsey: Unlocking energy efficiency in the U.S. Economy. McKinsey Global Energy and Materials (July 2009)

28. McKinsey: Big data: The next frontier for innovation, competition, and productivity. McKinsey Global Institute (May 2011)

29. McKinsey: Open data: Unlocking innovation and performance with liquid information, McKinsey Global Institute, McKinsey Center for Government and McKinsey Business Technology Office (2013a)

30. McKinsey. Disruptive technologies: Advances that will transform life, business, and the global economy. McKinsey Global Institute (2013b)

31. Melville, N.: Information Systems Innovation for Environmental Sustainability. MIS Quarterly 34(1), 1-21 (2010)

32. Merton, T.: Social Theory and Social Structure. Free Press, New York (1949)

33. Moore, M.H.: Creating Public Value Strategic Management in Government. Harvard University Press, Boston (1995)

34. Murray, R., Caulier-Grice, J., Mulgan, G.: The Open Book of Social Innovation (2010), http: / /www. nesta.org.uk/publications/open-book-socialinnovation

35. Nilsen, K.: Economic theory as it applies to Public Sector Information. Annual Review of Information Science and Technology 44(1), 419-489 (2010)

36. Nolan, J.M., Schultz, P.W., Cialdini, R.B., Goldstein, N.J., Griskevicius, V.: Normative social influence is underdetected. Personality and Social Psychology Bulletin 34, 913-923 (2008)

37. OECD: Fostering Innovation to Address Social Challenges. Workshop Proceedings (2011), http://www. oecd.org/sti/inno/47861327.pdf

38. Porter, M.E., Kramer, M.R.: Creating Shared Value. Harvard Business Review 89(1), 62-77 (2011)

39. Reinholt, M., Pedersen, T., Foss, N.J.: Why a Central Network Position isn't Enough: The Role of Motivation and Ability for Knowledge Sharing in Employee Networks. Academy of Management Journal 54(6), 1277-1297 (2011)

40. Rothchild, M.L.: Carrots, Sticks, and Promises: A Conceptual Framework for the Management of Public Health and Social Issue Behaviors. Journal of Marketing 63(4), 24-37 (1999)

41. Schultz, P.W., Nolan, N.J., Cialdini, R.B., Goldstein, N.J., Griskevicius, V.: The Constructive, Destructive, and Reconstructive Power of Social Norms. Psychological Science 18(5), 429-435 (2007)

42. Schumpeter, J.A.: The Theory of Economic Development. Harvard University Press, Boston (1934)

43. Siemsen, E., Roth, A.V., Balasubramanian, S.: How motivation, opportunity, and ability drive knowledge sharing: The constraining-factor model. Journal of Operations Management 26(2008), 426-445 (2008)

44. Shapiro, C., Varian, H.R.: Information Rules: A Strategic Guide to the Network Economy. Harvard Business School Press, Boston (1999)

45. Shogren, J.: Behavioural Economics and Environmental Incentives. OECD Environment Working Papers 49. OECD Publishing (2012)

46. Simon, H.: A Behavioral Model of Rational Choice. Models of Man, Social and Rational: Mathematical Essays on Rational Human Behavior in a Social Setting. Wiley, New York (1957)

47. Stiglitz, J.E., Sen, A., Fitoussi, J.P.: Report by the Commission on the Measurement of Economic Performance and Social Progress, OECD (2009) 
48. Tammisto, Y., Lindman, J.: Definition of open data services in software business. In: Cusumano, M.A., Iyer, B., Venkatraman, N. (eds.) ICSOB. LNBIP, vol. 114, pp. 297-303. Springer, Heidelberg (2011)

49. Tsang, E.W.K.: Behavioral assumptions and theory development: The case of transaction cost economics. Strategic Management Journal 27(11), 999-1011 (2006)

50. van Osch, W., Avital, M.: Generative Collectives. In: Proceedings of the International Conference on Information Systems (ICIS), Saint Louis, Missouri (2010)

51. van Veenstra, A.F., van den Broek, T.A.: Opening Moves - Drivers, Enablers and Barriers of Open Data in a Semi-public Organization. In: Wimmer, M.A., Janssen, M., Scholl, H.J. (eds.) EGOV 2013. LNCS, vol. 8074, pp. 50-61. Springer, Heidelberg (2013)

52. Vestergaard, J., Wade, R.: Establishing a new Global Economic Council: governance reform at the G20, the IMF and the World Bank. Global Policy 3(3), 57-69 (2012)

53. von Krogh, G., Haefliger, S., Spaeth, S., Wallin, M.W.: Carrots and Rainbows: Motivation and Social Practice in Open Source Software Development. MIS Quarterly 36(2), 649-676 (2012)

54. Weber, E.U., Johnson, E.J.: Psychology and Behavioral Economics Lessons for the Design of a Green Growth Strategy. White Paper for Green Growth Knowledge Platform, OECD, UNEP, World Bank (2012)

55. Williamson, O.E.: The Vertical Integration of Production: Market Failure Considerations. The American Economic Review 61(2), 112-123 (1971)

56. Williamson, O.E.: Transaction Cost Economics: The Process of Theory Development. In: Smith, K.G., Hitt, M.A. (eds.) Great Minds in Management: The Process of Theory Development, pp. 485-508. Oxford University Press, Oxford (2005)

57. Yu, H., Robinson, D.G.: The New Ambiguity of 'Open Government'. 59 UCLA Law Review (2012), http: / / ssrn. com/abstract $=2012489$

58. Zuiderwijk, A., Janssen, M., Choenni, S., Meijer, R., Alibaks, R.S.: Socio-technical Impediments of Open Data. Electronic Journal of e-Government 10(2), 156-172 (2012)

59. Zuiderwijk, A., Janssen, M.: Open Data Policies, Their Implementation and Impact: A Framework for Comparison. Government Information Quarterly 31(1), 17-29 (2014)

60. Ölander, F., Thøgersen, J.: Understanding of consumer behaviour as a prerequisite for environmental protection. Journal of Consumer Policy 18(4), 345-385 (1995) 